\title{
Identifikasi Ekosistem Usaha Mikro, Kecil dan Menengah (UMKM) Sebagai Pendukung Desa Wisata Rawabogo, Kecamatan Ciwidey, Kabupaten Bandung
}

\author{
Fadhilla Ihsani Aztamurri* \\ Prodi Teknik Perencanaan Wilayah \& Kota, Fakultas Teknik, \\ Universitas Islam Bandung, Indonesia. \\ *fadhillaihsaniaztamurri@gmail.com
}

\begin{abstract}
Rawabogo Village is one of the tourist villages in Ciwidey District which has millions of potential enough to be used as supporters of a tourist village. Micro, small and medium enterprises (MSMEs) have an important role in supporting a village to become a tourist village. In addition, MSMEs also help increase economic growth such as creating job opportunities, thereby creating income and wealth, as well as reducing poverty. Therefore, identification of the MSME ecosystem was carried out to find out how far the ecosystem supports the existing MSMEs, as an effort to support the development of the Raawabogo Tourism Village. The method used in this research is the Qualitative Descriptive Method and the Likert Scale Method with the entrepreneurial ecosystem (EES) approach or the entrepreneurial ecosystem approach. The results of the analysis state that they do not support the MSME ecosystem because of the lack of support for the ecosystem, both from the village government and from the village community. This has resulted in MSMEs in Rawabogo Village being hampered by their development and having an impact on the development of tourist villages. Efforts are made in the form of CBT (Community Based Tourism) considering that in planning the tourism village, it does not involve the role of the community.
\end{abstract}

Keywords: Tourism Village Development, SME Ecosystem, Identification.

Abstrak. Desa Rawabogo merupakan salah satu desa wisata di Kecamatan Ciwidey yang memiliki berjuta potensi yang cukup dijadikan sebagai pendukung sebuah desa wisata. Usaha mikro, kecil dan menengah (UMKM) mempunyai peran penting dalam mendukung sebuah desa menjadi desa wisata. Selain itu, UMKM juga membantu meningkatkan pertumbuhan ekonomi seperti terciptanya peluang kerja, sehingga tercipta pendapatan dan kekayaan, serta mengurangi kemiskinan. Maka dari itu dilakukan pengidentifikasian terhadap ekosistem UMKM guna mengetahui sejauhmana menunjangnya ekosistem tersebut terhadap UMKM yang ada, sebagai upaya pendukung pengembangan Desa Wisata Raawabogo. Metode yang digunakan dalam penelitian ialah metode skala likert dan metode deskriptif kualitatif dengan pendekatan the entrepreneurial ecosystem (EES) atau pendekatan ekosistem kewirausahaan. Hasil dari analisis menyatakan bahwa kurang menunjangnya ekosistem UMKM disebabkan kurangnya support terhadap ekosistem tersebut, baik dari pihak pemerintah desa maupun dari pihak masyarakat desa. Hal ini mengakibatkan UMKM di Desa Rawabogo menjadi terhambat perkembangannya serta ikut berdampak kepada pengembangan desa wisata. Dilakukannya upaya berupa CBT (Community Based Tourism) mengingat dalam perencanaan pada desa wisata tidak sedikit melibatkan peran masyarakat.

Kata Kunci: Pengembangan Desa Wisata, Ekosistem UMKM, Identifikasi. 


\section{A. Pendahuluan}

Menurut Inskeep menyatakan bahwa Desa wisata merupakan sekelompok kecil wisatawan yang tinggal di desa-desa terpencil atau di sekitar kehidupan tradisional, serta mempelajari lingkungan dan kehidupan desa setempat. Desa wisata ialah suatu bentuk kombinasi antara akomodasi, atraksi dan fasilitas penunjang yang distrukturkan dalam kehidupan masyarakat yang disatukan dengan tradisi dan tata cara yang berlaku. Menurut Pearce, pengembangan desa wisata merupakan suatu proses yang menonjolkan cara untuk meningkatkan dan mengembangkan desa wisata. Secara detailnya, peningkatan desa wisata dilakukan dengan usaha-usaha untuk melengkapi serta peningkatan fasilitas wisata untuk memenuhi kebutuhan wisatawan.

Desa Rawabogo merupakan salah satu desa wisata di Kecamatan Ciwidey yang merupakan salah satu dari sepuluh desa wisata di Kabupaten Bandung yang ditetapkan berdasarkan Keputusan Bupati Kabupaten Bandung pada tahun 2011. Menurut Andhika menyatakan bahwa terdapat banyak potensi di Desa Rawabogo yang cukup dijadikan sebuah desa wisata. Salah satu potensi yang dimiliki ialah sebuah Objek Gunung yang disebut Gunung Padang.

Di setiap negara usaha mikro, kecil dan menengah (UMKM) mempunyai peran penting dalam pertumbuhan ekonomi. Seperti terciptanya peluang kerja, sehingga tercipta pendapatan dan kekayaan, serta mengurangi kemiskinan. Menurut Bauchet and Morduch \& Saviovschi and Robu, UMKM merupakan entitas ekonomi yang disukai dan merupakan adaptasi yang mudah dan cepat. UMKM atau berwirausaha dapat menjalin silaturrahmi antar sesama manusia, saling membantu dalam hal memenuhi kebutuhan serta pastinya saling mendapat keuntungan. Perdagangan tidak hanya ditunjukan pada aktivitas transaksi dalam pertukaran suatu barang tertentu, tapi juga ditunjukkan pada sikap seseorang terhadap ketaatannya pada Allah SWT. Dalam artikata bahwa perdagangan meliputi pengertian eskatalogis, yakni dagang yang bersifat ibadah, seperti yang disampaikan dalam Surat Ash-Shaf ayat 10-11, yang berbunyi:

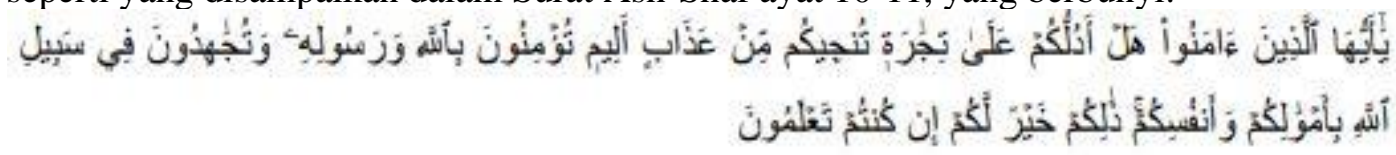

"Hai orang-orang yang beriman, sukakah kamu aku tunjukkan suatu perniagaan yang dapat menyelamatkanmu dari azab yang pedih? (yaitu) kamu beriman kepada Allah dan RasulNya dan berjihad di jalan Allah dengan harta dan jiwamu. Itulah yang lebih baik bagimu, jika kamu mengetahui".

Pendekatan dengan ekosistem kewirausahaan memfokuskan peran kewirausahaan dalam kebijakan ekonomi, mengulas sebagaimana pentingnya wirausahawan sebagai inti/dasar dalam menciptakan dan pemeliharaan sistem. Menurut Kline et al. menyatakan elemen penelitian (Pendekatan Ekosistem Kewirausaaan) ini dilakukan untuk menentukan apa yang menjadi pengaruh terbesar dalam pariwisata dan kewirausahaan. Menurut Stam \& Spigel dengan aspek kewirausahaan ditambahkan dalam konsep ekosistem, maka pendekatan ekonomi kewirausahaan (EES) dapat digambarkan sebagai sistem, di mana kewirausahaan terjadi dalam komunitas pelaku yang saling berhubungan atau bergantung. Konsep tersebut menggambarkan bagaimana kewirausahaan dimungkinkan oleh para pelaku yang memiliki peran penting dalam kegiatan kewirausahaan.

Di Desa Rawabogo saat ini, sudah terdapat beberapa UMKM yang berjalan, UMKM tersebut terdiri dari berbagai komoditas yang tersebar. Namun demikian, masih banyak UMKM yang masih kurang dalam pengelolaannya serta pengembangan yang belum optimal, padahal banyak UMKM ataupun potensi UMKM yang dapat dioptimalkan kinerjanya. Pendekatan ekosistem kewirausahaan (EES) membantu mengoptimalkan UMKM dalam upaya pengembangan Desa Wisata Rawabogo. Dengan penggunaan pendekatan ekosistem kewirausahaan ini, bertujuan untuk menentukan apa yang memiliki pengaruh terbesar terhadap kewirausahaan dan pariwisata.

Sehingga dalam penelitian ini dilakukan pengidentifikasian ekosistem usaha mikro, kecil dan menengah (UMKM) di Desa Rawabogo berdasar persepsi masyarakat lokal. Temuan 
ini menjelaskan dan memperkuat hasil pendekatan ekosistem kewirausahaan (EES) di Desa Rawabogo. Hasilnya dapat berupa kondisi existing dari ekosistem UMKM yang nantinya akan dibentuk beberapa rekomendasi kepada pemerintah dan masyarakat desa setempat dalam membenahi ekosistem UMKM kedepannya. Sehingga pengidentifikasian UMKM perlu dikakukan sebagaimana nantinya menjadi pendukung Desa Rawabogo menjadi sebuah desa wisata yang lebih optimal.

Berdasarkan latar belakang yang telah diuraikan, maka perumusan masalah dalam penelitian ini sebagai berikut:

1. Bagaimana kondisi ekosistem UMKM pada Desa Rawabogo?

2. Bagaimana ekosistem UMKM tersebut menjadi pendukung Desa Wisata Rawabogo?

Selanjutnya, tujuan dalam penelitian ini ialah mengidentifikasi dan mendeskripsikan keadaan ekosistem UMKM Desa Rawabogo sebagaimana menjadi pendukung pengembangan Desa Wisata Rawabogo.

\section{B. Metodologi Penelitian}

Peneliti menggunakan metode pendekatan analisis skala likert dan metode analisis deskriptif kualitatif dengan metode pendekatan ekosistem kewirausahaan atau the entrepreneurial ecosystem (EES). Pada variabel pendekatan ekosistem kewirausahaan diambil berdasarkan elemen penelitian Stam dan Van de Ven:

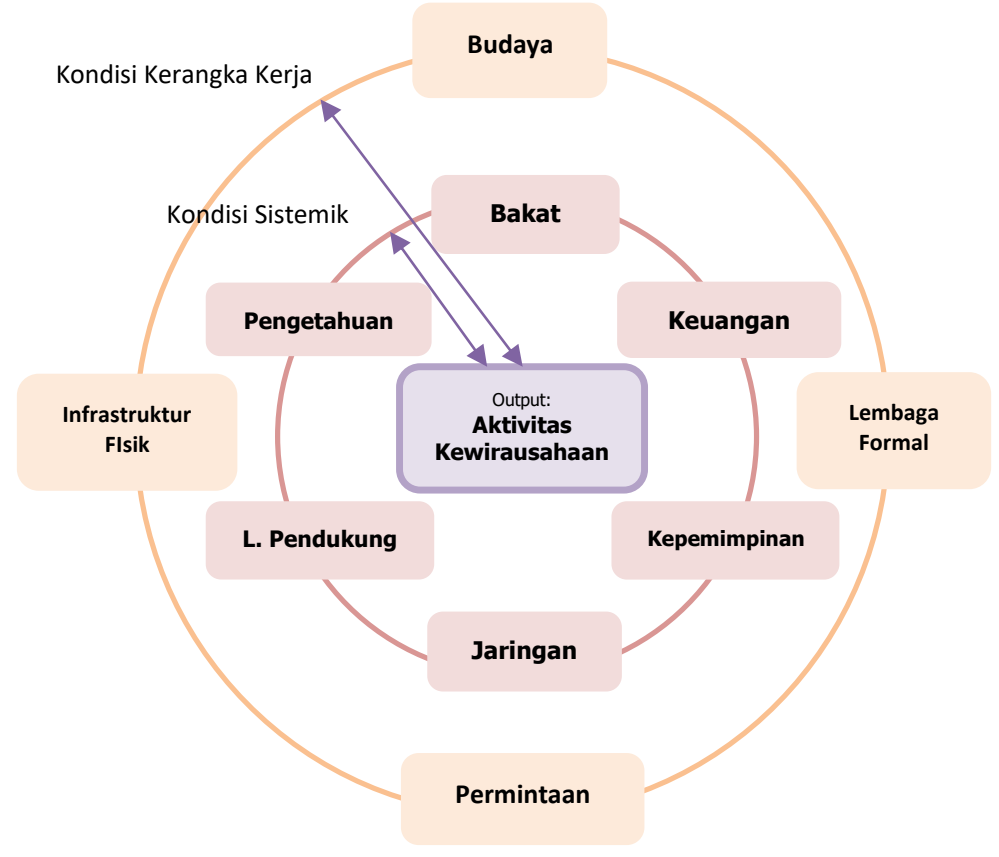

Gambar 1. Elemen Penelitian Van de Ven

Sumber: Stam \& van de Ven, 2018 
Berdasar elemen tersebut pada analisis pendekatan EES diproses menjadi 11 variabel dan 25 indikator sebagai berikut:

Tabel 1. Indikator

\begin{tabular}{|c|c|c|}
\hline No & Variabel & Indikator \\
\hline \multirow{3}{*}{1.} & \multirow{3}{*}{ Budaya } & a. Kekerabatan \\
\hline & & b. Kepercayaan \\
\hline & & c. Keterlibatan \\
\hline \multirow{3}{*}{2.} & \multirow{3}{*}{ Lembaga Formal } & a. Lembaga Pembiayaan \\
\hline & & b. Izin Usaha \\
\hline & & c. Pemerintah \\
\hline \multirow{2}{*}{3.} & \multirow{2}{*}{ Permintaan } & a. Barang \\
\hline & & b. Kesempatan kerja \\
\hline \multirow{3}{*}{4.} & \multirow{3}{*}{ Aksesibilitas } & a. Jalan \\
\hline & & b. Sarana transportasi \\
\hline & & c. Jaringan telekomunikasi \\
\hline \multirow{2}{*}{5.} & \multirow[t]{2}{*}{ Bakat } & a. Potensi \\
\hline & & b. Pesaing \\
\hline \multirow{3}{*}{6.} & \multirow{3}{*}{ Keuangan } & a. Sumber modal \\
\hline & & b. Pinjaman \\
\hline & & c. Pengelolaan Dana \\
\hline 7. & Kepemimpinan & a. Tata kelola \\
\hline \multirow{2}{*}{8.} & \multirow[t]{2}{*}{ Jaringan } & b. Kerjasama \\
\hline & & c. Target pasar \\
\hline 9. & Layanan Pendukung & a. Teknologi \\
\hline \multirow{4}{*}{10.} & \multirow{4}{*}{ Kreativitas } & a. Kreativitas dan Seni \\
\hline & & b. Pengiklanan/media \\
\hline & & c. Merek dagang \\
\hline & & d. Pemasaran \\
\hline 11. & Pengetahuan & $\begin{array}{l}\text { a. Pendidikan dan pelatihan mengenai } \\
\text { kewirausahaan }\end{array}$ \\
\hline
\end{tabular}

Sumber: Penulis, 2021.

Teknik pengumpulan data yang digunakan dalam penelian ini adalah observasi, wawancara dan kuesioner. Adapun yang menjadi responden di penelitian ini adalah:

Tabel 2. Responden Penelitian

\begin{tabular}{|l|l|}
\hline \multicolumn{1}{|c|}{ No. } & \\
\hline 1. & Usaha Cangkang Kopi \\
\hline 2. & Usaha Terasi \\
\hline 3. & Usaha Kebun Teh \\
\hline 4. & Usaha Pabrik Kopi \\
\hline 5. & Usaha Kripik Opak (singkong) \\
\hline 6. & Usaha Bolu \\
\hline 7. & Usaha Kaos Konveksi \\
\hline 8. & Usaha Olahan Pohon Kawung \\
\hline 9. & Usaha Tahu Crispy \\
\hline 10. & Usaha Kacang Asin \\
\hline
\end{tabular}


Tabel 3. Informan, Target yang Diharapkan dan Waktu

\begin{tabular}{|c|c|c|c|}
\hline No. & Informan & Target yang diharapkan & Waktu \\
\hline 1 & Kang Tedi (mantan Kompepar) & Indikator Ekosistem UMKM & Survey Lapangan \\
\hline 2 & Kang Wildan (pegawai desa) & Indikator Ekosistem UMKM & Survey Lapangan \\
\hline 3 & $\begin{array}{c}\text { Bapak H. Suhat (mantan pegawai } \\
\text { BUMDes sekaligus pelaku } \\
\text { UMKM) }\end{array}$ & Indikator Ekosistem UMKM & Survey Lapangan \\
\hline & \begin{tabular}{c} 
SMMan \\
\hline
\end{tabular}
\end{tabular}

Sumber: Penulis, 2021.

\section{Hasil Penelitian dan Pembahasan}

Analisis Ekosistem UMKM

Analisis dalam penelitian ini menggunakan analisis skala likert yang bertujuan untuk mengukur suatu sudut pandang atau pendapat seseorang/sekelompok terhadap suatu peristiwa atau fenomena. Dari perhitungan skala likert (yang diuraikan di lampiran) menggunakan rumus di atas, didapatlah data dan perhitungan dari Lembar Kuesioner sebagai berikut:

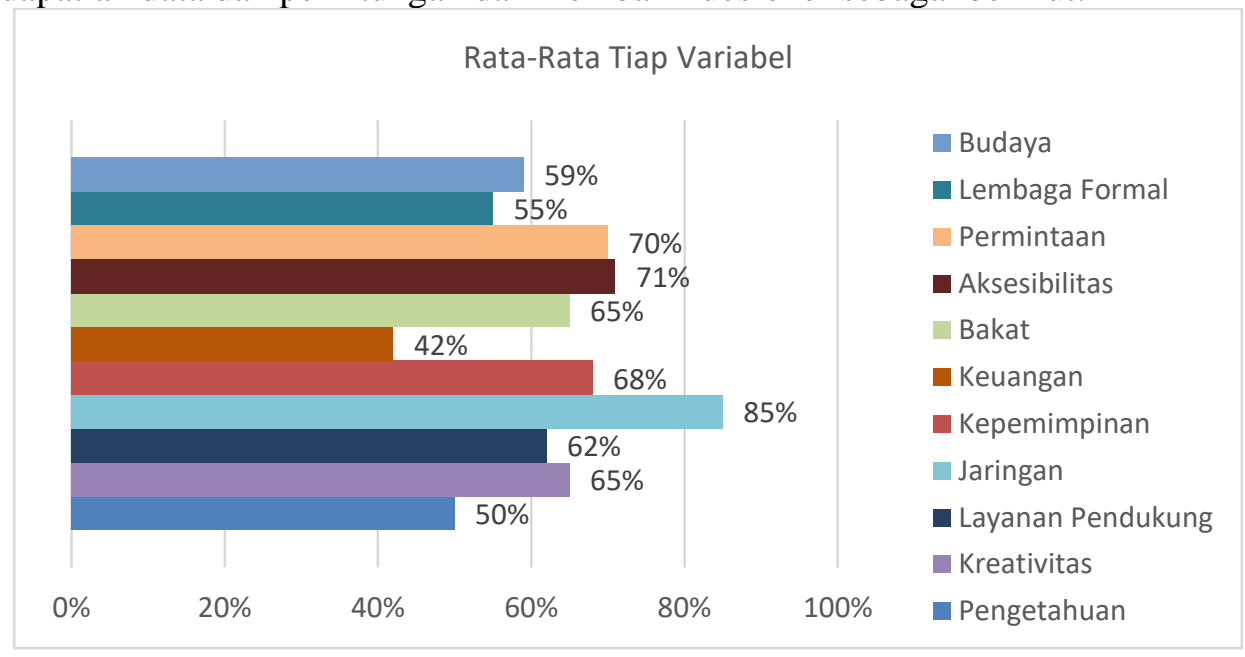

Gambar 2. Rata-rata Tiap Variabel

Sumber: Hasil Analisis, 2021.

Dapat dilihat bahwa dalam ekosistem UMKM tersebut, variabel yang kurang menunjang ialah variabel keuangan $(42 \%)$, variabel pengetahuan $(50 \%)$, variabel lembaga formal $(55 \%)$ dan lembaga budaya (59\%). Sedangkan kategori variabel yang menunjang adalah layanan pendukung (62\%), bakat (65\%), kreativitas (65\%), kepemimpinan (68\%), permintaan (70\%) dan aksesibilitas (71\%). Variabel yang sangat menunjang terdapat pada variabel jaringan $(85 \%)$.

Berdasarkan hasil analisis di atas, ekosistem UMKM dalam Desa Rawabogo masih terbilang kurang menunjang. Dilihat dari variabel budaya, dikatakan kurang karena ternyata dengan adanya kegiatan kekerabatan seperti TAKORA (Taman Kota Rawabogo) dan pertemuan-pertemuan yang dilakukan bukan menjadi penyebab munculnya UMKM baru. Andaikata pertemuan-pertemuan tersebut bisa dioptimalkan dan dimaksimalkan, maka bisa membantu terlahirnya UMKM-UMKM yang baru.

Ditinjau dalam variabel lembaga formal, lembaga-lembaga yang ada masih sangat kurang dalam hal menunjang UMKM. Seperti tidak adanya lembaga pembiayaan yang membantu pendanaan UMKM hingga lembaga dari pemerintah sendiri yang tidak memprakarsai dan tidak memerhatikan tumbuh kembangnya UMKM.

Dalam aksesbilitas, dikatakan kurang karena akses jalan dari/ke UMKM yang masih belum memadai. Terdapatnya beberapa titik jalan yang masih rusak dan belum diperbaiki oleh pihak desa. Hal ini bisa mengakibatkan terhambatnya mobilisasi produksi, penjualan hingga pemasaran dari UMKM itu sendiri. 
| Fadhilla Ihsani Aztamurri, et al.

Terkait keuangan, UMKM yang terdapat di Desa Rawabogo masih terbilang lemah dalam pendanaan. Mulai dari sumber modal yang tidak didapat sama sekali oleh pelaku UMKM, baik dari dalam maupun luar desa. Semata-mata hanya menggunakan dana pribadi yang mereka punya atau persiapkan. Selain itu, pelaku UMKM juga tidak melakukan peminjaman dana dari dalam/luar desa, yang mana memang tidak ada lembaga yang memfasilitasi program peminjaman tersebut. Andaikata ingin menjalankan usaha baru atau upgrade usaha yang lama, pelaku tidak bisa mendapatkan dana tambahan, sehingga memilih untuk tidak melanjutkan keinginan tersebut. Selain itu UMKM yang ada juga belum melakukan pengelolaan dana dengan baik. Masih menggunakan metode lama, yakni setelah mendapat keuntungan langsung digunakan kembali untuk pembelian bahan. Tanpa ada pembukuan atau perhitungan terlebih dahulu.

Dilihat berdasar kreativitas, dari sekian indikator, UMKM masih kurang di bagian pemasaran pada marketplace. Sudah banyak wadah yang telah disediakan untuk pengembangan pemasaran dari produk usaha, yang semestinya bisa dimanfaatkan keberadaannya. Jika lebih kreatif dan lebih dioptimalkan penggunaannya, maka akan sangat membantu dalam proses pemasaran produk dari UMKM itu sendiri.

Minimnya pembinaan tentang kewirausahaan mengakibatkan minimnya juga pengetahuan yang dimiliki. Hal ini berdampak kurang berkembangnya UMKM serta tidak adanya inovasi yang dilakukan. Masih merasa takut untuk berjalan lebih maju ke depan karena kurangnya pengetahuan dan basic seputar kewirausahaan tersebut.

Berdasarkan semua kekurangan pada ekosistem UMKM tersebut, bisa disimpulkan bahwa penyebab utamanya ialah dari pemerintah dan pelaku UMKM itu sendiri. Kurangnya perhatian dari pemerintah mengakibatkan kekurangan-kekurangan lainnya bermunculan, seperti tidak adanya lembaga pembiayaan yang membantu pendanaan UMKM, tidak adanya sumber modal serta tidak adanya bantuan pinjaman. Selain itu, kecuekan pemerintah tersebut juga berdampak pada pembinaan/pendidikan mengenai kewirausahaan. Padahal, jika pemerintah ikut turun tangan dalam hal ini, maka pembinaan/pendidikan mengenai kewirausahaan tersebut bisa dilakukan, sehingga dalam pengelolaan dana dan pemasaran marketplace pun ikut terbantu. Begitupun aksesbilitas seperti akses jalan yang semestinya harus lebih diperhatikan, karena tidak hanya dari segi UMKM yang membutuhkan akses jalan yang bagus, semua masyarakat dan pendatang juga membutuhkannya. Selain pemerintah yang sebagai penyebab, masyarakat atau pelaku UMKM juga bisa dikategorikan sebagai penyebab di sini. Kurang gesitnya masyarakat akan hal kewirausahaan juga berdampak tidak majunya UMKM yang ada. Mulai dari segi hal kekerabatan, yang semestinya bisa dioptimalkan oleh pelaku UMKM/masyarakat untuk dijadikan peluang dalam membentuk suatu jaringan UMKM baru atau menjadi ladang inovasi yang baru.

Dari semua kekurangan pada ekosistem UMKM tersebut, sebaiknya pemerintah dan pelaku UMKM dalam pengembangan desa wisata harus lebih memerhatikan indikator-indikator yang masih terbilang lemah/kurang menunjang tersebut. Sangat disayangkan dengan sejuta potensi yang ada pada Desa Rawabogo, mengakibatkan menjadi kurang maju dikarenakan masih ada indikator ekosistemnya yang masih terbilang kurang akan hal menunjang UMKM.

\section{Pengembangan Desa Wisata}

Maksimalnya kondisi ekosistem UMKM akan berdampak pada pengembangan dan kemajuan UMKM. Hal ini berpengaruh pada pengembangan desa wisata Rawabogo, karena dalam desa wisata sendiri para pengunjung tidak hanya menilai dan menikmati dari atraksi wisatanya saja melainkan juga dari segi kuliner dan kerajinan tangan yang bisa dijadikan souvenir atau buah tangan. Selain itu, UMKM yang sudah dikenal namanya, yang sudah tidak diragukan lagi rasa dan kualitasnya, bisa membawa nama desa menjadi ikut dipandang dan dikenal. Tidak menutup kemungkinan masyarakat luar menjadi penasaran dan memutuskan untuk mengunjungi desa wisata Rawabogo, terlebih sebagai tempat asal produksinya.

Bisa dikatakan penyebab tidak berkembangnya desa wisata Rawabogo karena kurangnya support ekosistem UMKM tersebut. Seperti yang sudah dikatakan, bahwa dalam pengembangan desa wisata sendiri tidak hanya dilihat dari atraksi wisata melainkan juga dari 
segi UMKM, sehingga di sini diperlukan UMKM yang maju dan berkembang. Dengan begitu, jika UMKM sudah terbilang maju, maka dapat berdampak pada desa wisata yang juga ikutan berkembang.

Berdasarkan kondisi yang ada, maka perlu diambil langkah perencanaan untuk waktu dan kondisi yang akan datang. Perencanaan merupakan suatu keputusan apa yang diharapkan/diinginkan dalam waktu yang akan datang. Mengingat perencanan pada desa wisata tidak sedikit melibatkan peran, partisipasi dan pemberdayaan masyarakat, maka bentuk perencanaannya mengarah kepada Community Based Tourism (CBT).

Menurut Sunaryo (2013:138), mengemukakan bahwa community based tourism (CBT) merupakan strategi terhadap pengembangan pariwisata yang berfokus pada pemberdayaan masyarakat. Selain itu, menurut Suansri (2003:14) mendefinisikan CBT sebagai jenis pariwisata yang memerhatikan aspek kelestarian lingkungan, sosial dan budaya. CBT adalah alat untuk pengembangan masyarakat dan konservasi lingkungan. Dengan kata lain, CBT merupakan suatu langkah untuk mencapai pembangunan pariwisata yang berkelanjutan. Timothy (1999:372) menyatakan bahwa keterlibatan masyarakat dalam pariwisata terdiri dari dua sudut pandang, yaitu partisipasi lokal dalam pengambilan keputusan dan partisipasi lokal terkait dengan memanfaatkan yang diterima masyarakat dari pengembangan pariwisata.

Strategi ini menyadari bahwasanya kapasitas masyarakat memang penting untuk meningkatkan kemandirian dan kapasitas internal dalam mendalami kondisi dan kehidupan pedesaan dari dengan / oleh masyarat desa, yang biasa disebut dengan pendekatan Participatory Planning. Dapat dijelaskan sebagai metode yang memungkinkan masyarakat desa untuk bersama-sama berbagi meningkatkan dan menelaah pengetahuan mereka mengenai kondisi dan kehidupan desa terlebih UMKM, hingga membuat suatu rencana dan bertindak.

Desa wisata yang berpijak pada masyarakat merupakan suatu alternatif baru untuk mengembangkan serta meningkatkan hasil produksi, terlebih campur tangan pemerintah yang masih sangat minim.

\section{Kesimpulan}

Berdasarkan pembahasan dalam penelitian ini, peneliti menyimpulkan beberapa hasil penelitian sebagai berikut:

Kesimpulan ini menjawab rumusan masalah dan tujuan penelitian yaitu berupa mengetahui keadaan dari tiap ekosistem UMKM sebagai upaya pengembangan Desa Wisata Rawabogo. Dari uraian analisis di atas, dapat disimpulkan bahwa kurang menunjangnya ekosistem UMKM di Desa Rawabogo mengakibatkan terhambatnya perkembangan UMKM yang ada. Dengan hasil rata-rata nilai variabel dikategorikan menjadi 3 bagian: kategori kurang menunjang $(41-60 \%)$ yaitu keuangan $(42 \%)$, pengetahuan $(50 \%)$, lembaga formal $(55 \%)$, budaya (59\%); kategori menunjang $(61-80 \%)$ yaitu layanan pendukung $(62 \%)$, bakat $(65 \%)$, kreativitas (65\%), kepemimpinan (68\%), permintaan (70\%), aksesibilitas (71\%); dan lategori sangat menunjang (81-100\%) yaitu jaringan (85\%).

Pada variabel keuangan, semua indikatornya yaitu sumber modal, pinjaman serta pengelolaan dana masih terbilang kurang menunjang. Selain varibel keuangan, terdapat beberapa variabel yang juga terbilang kurang dalam hal menunjang UMKM, seperti variabel pengetahuan, variabel lembaga formal dan variabel budaya.

Kurang menunjangnya ekosistem UMKM disebabkan kurangnya support `terhadap ekosistem tersebut, baik dari pihak pemerintah desa maupun dari pihak masyarakat desa. Hal ini juga yang mengakibatkan UMKM di Desa Rawabogo menjadi terhambat perkembangannya. Begitupun perkembangan desa wisata yang ikut tidak berkembang karena UMKM yang tidak berkembang dan tidak maju, karena dalam pengembangan desa wisata diperlukan UMKM yang maju.

Untuk itu dilakukanlah upaya atau langkah agar mengatasi masalah ini ke depannya, melakukan perencanaan terhadap desa wisata Rawabogo agar lebih bisa dikembangkan. Menggunakan Konsep CBT (Community Based Tourism)-lah yang mungkin cocok untuk digunakan, mengingat dalam perencanaan pada desa wisata tidak sedikit melibatkan peran masyarakat. Walaupun masyarakat banyak ikut andil dan banyak terlibat, namun perhatian dan 
kesadaran pemerintah juga sangat diperlukan di sini.

\section{Acknowledge}

Alhamdulillah, Puji dan syukur senantiasa dipanjatkan kepada Allah SWT, atas limpahan rahmat dan karunia-Nya yang telah diberikan, sehingga penulis dapat menyelesaikan Tugas Akhir dengan judul "Identifikasi Ekosistem Usaha Mikro, Kecil dan Menengah (UMKM) Sebagai Pendukung Desa Wisata Rawabogo, Kecamatan Ciwidey, Kabupaten Bandung”.

Selama penulisan Tugas Akhir ini, penulis mendapat bantuan dan bimbingan dari berbagai pihak. Maka dari itu, praktikan mengucapkan terimakasih yang sebesar-besarnya kepada:

1. Kepada Allah SWT;

2. Kepada Orang Tua dan Keluarga/Kerabat tercinta yang telah memberikan dorongan dan motivasi baik secara materil maupun moril;

3. Kepada Bapak Dr. Imam Indratno, ST., MT. Selaku Dosen Pembimbing yang telah memberikan bimbingan dan meluangkan waktunya untuk membimbing penulis;

4. Kepada Ibu Astri Mutia Ekasari, Ir., MT. Selaku Koordinator Tugas Akhir;

5. Serta teman-teman dan semua pihak yang tidak disebutkan satu per satu atas bantuan juga motivasi untuk tetap semangat dalam mengerjakan Tugas Akhir.

Untuk penyempurnaan penyusunan jurnal ini, penulis dengan senang hati terbuka untuk menerima kritik dan saran yang dapat membangun perkembangan jurnal Tugas Akhir penulis. Akhir kata, semoga penyusunan poposal ini dapat bermanfaat bagi civitas akademika dan khalayak umum.

\section{Daftar Pustaka}

[1] Alamsyah, M. N. (2011). Memahami perkembangan desa di indonesia. ACADEMICA Fisip Untad, 03(02), 647-660.

[2] Anggraeni, F. D., Hardjanto, I., \& Hayat, A. (2013). Pengembangan Usaha Mikro, Kecil, Dan Menengah (UMKM) Melalui Fasilitasi Pihak Eksternal Dan Potensi Internal. Jurnal Administrasi Publik, 1(6), 1286-1295.

[3] Bismantara, B. (2013). Analisa Peran Kepemimpinan dalam Usaha Kecil dan Menengah Industri Kreatif. Jurnal Dimensia, 10(2), 81-112. https://ejournal.stiesa.ac.id/file.php?file=jurnal\&id=60\&cd=0b2173ff6ad6a6fb09c95f6d 50001df6\&name $=02$ dimensia vol 10 no 2 bisma analisa peran kepemimpinan.pdf

[4] Fiati, R. (2016). Strategi Pengembangan Jaringan Usaha UMKM. Jurnal DIANMAS, 5(April), 53-62.

[5] Geogra, F., \& Gadjah, À. U. (2013). Pengembangan Desa Wisata Berbasis Partisipasi Masyarakat Lokal Di Desa Wisata Jatiluwih Tabanan, Bali. Jurnal Kawistara, 3(2), 129139. https://doi.org/10.22146/kawistara.3976

[6] Hafni, R., \& Rozali, A. (2017). Analisis Usaha Mikro, Kecil, dan Menengah (umkm) terhadap Penyerapan Tenaga Kerja di Indonesia. Ilmu Ekonomi Dan Studin Pembangunan, 15(2), 77-96. http://jurnal.umsu.ac.id/index.php/ekawan/article/view/1034/pdf_58

[7] Hariyanto, O. I. B., \& Sihombing, D. A. (2019). Tradisi Ritual Masyarakat Desa Rawabogo Ciwidey Sebagai Daya Tarik Desa Wisata. Altasia: Jurnal Pariwisata Indonesia, 1(1), 33-38. https://doi.org/10.37253/altasia.v1i1.338

[8] Joshi, A., Kale, S., Chandel, S., \& Pal, D. (2015). Likert Scale: Explored and Explained. British Journal of Applied Science \& Technology, 7(4), 396-403. https://doi.org/10.9734/bjast/2015/14975

[9] Kurniawan. (2014). Faktor yang mempengaruhi akses keuangan pinjaman usaha mikro kecil dan memengah (UMKM) di Kabupaten Brebes. Jounal \& Proceding FEB Universitas Soedirman, 4(2014), 611-621.

[10] Latif, N., Suharyanto, Adi, B., Lasiyono, U., \& Miradji, M. A. (2021). Digitalisasi Pengajuan IzinUsaha UMKM di Desa Banjarkemantren, Kecamatan Buduran, Kabupaten Sidoarjo. 
Pengabdian Masyarakat, 1, 92-101.

[11] Mudjiarto, \& Sugiharto, A. (2014). Pembinaan Usaha Menengah, Kecil \& Mikro (UMKM) Melalui Program Kemitraan \& Bina Lingkungan (PKBL) BUMN. 1.

[12] Prabowo, S., Hamid, D., \& Prasetya, A. (2016). ANALISIS PARTISIPASI MASYARAKAT DALAM PENGEMBANGAN DESA WISATA (Studi Pada Desa Pujonkidul Kecamatan Pujon Kabupaten Malang). Jurnal Administrasi Bisnis S1 Universitas Brawijaya, 33(2), 18-24.

[13] Purmada, D., Wilopo, W., \& Hakim, L. (2016). PENGELOLAAN DESA WISATA DALAM PERSPEKTIF COMMUNITY BASED TOURISM (Studi Kasus pada Desa Wisata Gubugklakah, Kecamatan Poncokusumo, Kabupaten Malang). Jurnal Administrasi Bisnis S1 Universitas Brawijaya.

[14] Rais, S. A. (2020). Pengaruh Mekanisme Pasar Dengan Usaha Mikro, Kecil, Dan Menengah (Umkm). Pasar Dengan Usaha Mikro, Kecil, Dan ..., 1-17. http://eprints.umsida.ac.id/6892/

[15] Rudiatin, E., \& Ramadhan, A. I. (2018). Kekuatan Moral dan Budaya, Mendukung Perekonomian Indonesia: Sebuah Gambaran Usaha Kecil dan Menengah. BASKARA Journal of Business \& Entrepreneurship, 1(1), 21-34. https://jurnal.umj.ac.id/index.php/baskara/article/view/3117

[16] Rumijati, A. (2010). Pengaruh Bakat Potensi Kewirausahaan Dan Metode Pembelajaran Terhadap Minat Berwirausaha Mahasiswa. Ekonomika-Bisnis, 1(2), 187-200.

[17] Sudarwati, Y., \& Eka Satya, V. (2013). Strategi Pengembangan Merek Usaha Mikro, Kecil, dan Menengah. Jurnal Ekonomi \& Kebijakan Publik, 4(1), 89-101.

[18] Widihastuti, R., \& Huda, M. (2019). AKSESIBILITAS LEMBAGA PEMBIAYAAN FORMAL UNTUK PELAKU USAHA MIKRO PENGOLAHAN IKAN DI KABUPATEN GRESIK Accessibility of Formal Financing Institution for Micro Business Actors of Fish Processing in the Gresik District. 249-259.

[19] Wijaya, I. D. P. A., Fernanda, I. P. H., Yudiana, I. K. febi, \& Wisesa, I. gusti A. P. A. D. (2021). Analisis Strategi Pemasaran UMKM Dimasa Pandemi Melalui Fitur TopAds Pada E-Commerce (Analysis of MSME Marketing Strategies During the Pandemic Period through the TopAds Feature in e-Commerce). Seminar Nasional Desain, 1, 1-8. https://eproceeding.isi-dps.ac.id/index.php/sandi-dkv/article/view/133 